\title{
The changing relationship between the Scholarship of Teaching (and Learning) and universities
}

This paper contextualises this special issue on the relationship between institutions of higher education and the Scholarship of Teaching and Learning (SoTL). It provides an overview of SoTL's gradual incorporation into institutions in a time of wide ranging educational and political change. Through this discussion it examines the place and the relevance of SoTL to universities predominantly in the western world. In so doing, it lays the basis for the papers in this issue which examine how various institutions have responded to, promoted, developed and incorporated SoTL into their processes, how well SoTL has aligned with institutional objectives, the institutional challenges in addressing SoTL and the implications for SoTL for the future.

\section{The developing institutional interest in Scholarship of Teaching (and Learning)}

It has been nearly 20 years since Boyer fired the imagination of governments, universities, and academics with the notion of the Scholarship of Teaching (SoT), one of four separate yet overlapping forms of scholarship that he claimed represented the "work of the professoriate" (Boyer, 1990 p.16). Boyer argued for an elevation of teaching (through the notion of scholarship) to a status equal to research, claiming that teaching was at the core of the university. Here was a concept with the potential to address a number of issues plaguing the higher education sector worldwide: how to get academic staff and their institutions to take their teaching as seriously as they take their research; how to reward staff for teaching well; and how to enculturate "new blood" into the academy.

Since then, the concept has been examined and debated (Andresen, 2000; Boyer, 1990, p. 65; Huber \& Morreale, 2002; Kreber, 2002; Smith, 2001; Trigwell, Martin, Benjamin, \& Prosser, 2000; Weston \& McAlpine, 2001; Willox \& Lackeyram, 2009), and this debate continues today. While it is commonly agreed that the SoT involves reflection on and enquiry into classroom teaching and its impacts on learning, other questions have arisen. Is informal reflection sufficient or does SoT refer to a more formal process of research into practice? Is it necessary to undertake research into teaching or is it sufficient to be informed and use the outcomes of research? Are there developmental stages in becoming a scholar of teaching? Should SoT focus on contexts beyond the classroom? Is it situated only within disciplines? Where does SoT sit in relation to student experiences that go beyond their course and class-related learning?

Despite these debates, recognition of the strong relationship between teaching and learning resulted in a subtle shift both in name and focus. The Scholarship of Teaching (SoT) gradually became referred to as the Scholarship of Teaching and Learning (SoTL), reflecting the student focussed stance advocated in the literature and adopted by many practitioners and institutions (Hutchings \& Shulman, 1999). This signalled a shift from Boyer's (1990) over-riding attention to the outcomes of teaching to a more intense focus on the process of teaching and learning. Boyer saw the outcomes of the SoT being the development of scholarly habits and dispositions in students so that they may "serve and 
reshape society" (Boyer, 1990 p. 6) and so that the academy could ensure the "new generation of scholars"(Boyer, 1990 p. 65). However, the SoTL process oriented approach focuses on the impacts of teaching on the students' learning experience irrespective of Boyer's intended outcomes. This changed agenda meant that SoTL came to be seen by some as a means to address perceived deficits in teaching, and hence the learning experience. This provided a place for SoTL in the quality assurance agenda (Chalmers, in this publication). Engagement in SoTL could be the means of both evaluating and improving the quality of the educational experience. Accordingly, funding bodies, governments and universities gradually incorporated SoTL into policies, plans and professional development programs (Haigh, Gossman, \& Jiao, in this publication).

With SoTL being firmly aligned with quality in teaching and learning, it was also seen as another way of providing evidence of "good teaching", and hence by implication, "good learning". We see this now in the greater emphasis being placed on publicly rewarding 'good teachers', through national and institutional awards and citations (Chalmers, in this publication). These typically require evidence of 'scholarship' in teaching as defined by the awarding body. To further improve quality, several countries also offer a range of funding opportunities for scholarly activities in teaching and learning in the form of grants and fellowships to undertake research into teaching and learning, develop and evaluate educational initiatives, and establish networks and centres devoted to the development of teaching and learning (Australian Learning and Teaching Council, 2009; Higher Education Funding Council for England, 2007).

The increase in awards, funding and national recognition have provided SoTL with a status that makes it more highly valued by institutions. Coupled with its strong conceptual alignment with quality, evidence of successful engagement in SoTL, in whichever way it has been defined (if any), has been increasingly required for academic promotion with many universities incorporating it into their promotions criteria (Boshier, 2009; Vardi \& Quin, in this publication).

However, while the concept of SoT(L) was changing and being incorporated into the fabric of tertiary institutions, the educational context for universities in the western world has also been changing (Paewai, Meyer, \& Houston, 2007). Not only have contextual changes impacted significantly on teaching staff, they have also impacted on university perceptions, expectations and demands of SoTL resulting in some interesting tensions as well as opportunities.

\section{The changing educational context}

Over the past 20 years, the educational context in the western world has changed in a number of key ways. A major change has been the enormous increase in student numbers resulting from international student growth and increased domestic participation. A second change, in part a result of the first, is the change in the nature of the student population - no longer an elite cohort but a student body with very different learning needs and aspirations. The resultant diversity coupled with increased numbers has made significant demands on teachers and has been perceived by many as a hindrance to effective teaching (McInnis, 1999). These demands on teachers have resulted in a need 
for changes to be made in how teaching and assessment is carried out in order to better cater for differing backgrounds and learning styles. This challenge has been made all the more difficult by the lack of concomitant resources for staffing (Burgess, 1996; Coldrake, 1999) resulting in the increasing acceptance and use of "adjunct models" for teaching (Cranton, 2010).

Alongside the growth in the diversity and increase in the number of students, has been the astounding growth in the use of information technology. Information technologies have become a core part of teaching and hence the learning experience. Academic staff have had to discover the possibilities that new technologies offer, how to use them, and how to effectively incorporate them into the learning environment. They have also had to discover how teaching and learning through these technologies differs from more traditional face-to face and distance education delivery. In addition, they have needed to trial these technologies across a range of modalities (e.g. face-to-face, totally online) simultaneously for students who may or may not be present at their campus.

At the same time, governments have been looking for increased accountability and productivity from universities. One effective way in which governments have sought to exercise control over universities to increase accountability and productivity is through the use of performance indicators (Taylor \& Taylor, 2003). A range of performance indicators are used at national levels across many countries to compare institutions' performance (Burke \& Modaressi, 2000). For many institutions these same indicators form part of their strategic plans and have "flowed down" to evaluation of their faculties', schools' and individuals' levels of performance (Taylor \& Taylor, 2003).

The use of performance indicators has directly impacted on how universities function with many adopting a corporate business focus (Winter \& Sarros, 2002) and the language of the 'New Public Management' (Olssen \& Peters, 2005) with words such as 'outputs, 'outcomes' and 'Key Performance Indicators' (KPIs). More than ever, universities are now strategically aligning all areas of their operations to deliver against their KPIs. Within this context, staff and the areas within which they work are held accountable for student satisfaction ratings, pass rates, enrolment numbers, retention rates, graduate employment rates, publication rates and the like, and of course gathering the evidence for these accountability measures.

These changes over the past 20 years in participation rates, technology and accountability measures have focussed and intensified academic work resulting in increased academic workloads (Anderson, Johnson, \& Saha, 2002; Coldrake, 1999; McInnis, 2000; Paewai et al., 2007; Vardi, 2009). Despite attempts to control workloads through a variety of workload models, academic workloads are typically being reported as being between 49 - 55 hours per week (Vardi, 2009) impacting on the industrial relations environment for academics. Attempts at workload control (often unsuccessful) have led institutions to consider additional measures to workload models. Of significance is the recognition by many institutions that some academics have neither the time nor expertise to effectively perform across all areas of academic work. As a result, a range of institutions are now starting to explicitly categorise staff as teaching-focussed (teaching only), teaching- 
research and research-focussed (research only) (Vardi \& Quin, in this publication). This changes the notion of and participation in the four areas of scholarship espoused by Boyer. While Boyer recognised that careers change over an academic's work life, sometimes emphasising some areas of scholarship over others, he also felt that all academic staff should adhere to some minimum expectations in all three areas of teaching, research and service (Boyer,1990 pp 51).

\section{Implications for SoTL and its relationship with universities}

In a KPI and market-driven environment, institutions require SoTL to contribute on a variety of fronts. In the face of increasing competition for student numbers, institutions need mechanisms to ensure high levels of student satisfaction and therefore retention, while demonstrating adherence to high standards through measures such as appropriate pass/fail rates - all this while being under continual pressure to change teaching practices in response to the changing environment. SoTL's "reflective practitioner" stance certainly provides one means of improving performance as new practices are trialled, reflected upon and improved. Yet evidence of this having an effect on student learning is limited (Haigh et al., in this publication; Mårtensson, Roxå, \& Olsson, in this publication). This may be due to the difficulties in measuring an objective effect on learning (Cranton, 2010) and a paucity of institutional or more broad based research on the impact of SoTL on student learning. However, this lack of evidence may also in part be due to the need for SoTL practice to move beyond the confines of the classroom and tackle wider institutional constraints and issues of concerns (Cranton, in this publication; Mårtensson et al., in this publication; Shreeve, in this publication; Vardi \& Quin, in this publication).

While the SoTL literature is mainly concerned with improving teaching and learning, institutional needs for SoTL go well beyond this. Institutions also need to provide reward, recognition and a career path for those whose focus is on teaching only (Chalmers, in this publication; Vardi \& Quin, in this publication). However, reward and recognition also needs to address the changing industrial relations environment for academic staff. It raises additional questions on what SoTL constitutes in practice and what it means for the most significant form of reward and recognition: promotion. This includes questions such as the following. What type and amount of SoTL should a teaching only staff member engage in to justify promotion? Should this include formal research into practice? How do the expectations in SoTL for a teaching only staff member compare with the expectations for a teaching-research staff member who already devotes time to research in their disciplinary area? Does the concept need to change to reflect differing work profiles?

While teaching, learning and their recognition have long been themes underlying SoTL, institutions also need to meet their KPIs in terms of research output. The requirements for increased output in research have placed further pressure on SoTL to provide a research pathway for teaching only staff so that they too can contribute to the research measures being applied to the university. These types of SoTL activities valued by institutions further affect the perception of what constitutes SoTL in the workplace. With broader institutional objectives also needing to be met, SoTL research may increasingly need to 
become aligned with broader institutional objectives in teaching and learning e.g. see (Shreeve, in this publication).

Within this ever changing educational context, how are different institutions responding to SoTL, how is SoTL in practice being changed in response to institutional needs, and what tensions and opportunities arise?

\section{This issue}

The papers in this issue address different aspects of the relationship between SoTL and the institutions within the current context. They provide snapshots of and insights into SoTL from institutional perspectives from across the world including North America, New Zealand, the United Kingdom, Sweden and Australia.

Two papers in this issue examine institutional practices across universities in relation to SoTL. The first of these two, Neil Haigh, Peter Grossman and Xiaomin Jiao's paper "Undertaking an institutional 'stock-take' of SoTL: New Zealand university case studies", examines how New Zealand institutions have incorporated SoTL in their rhetoric, actions and outcomes. It builds on "stocktakes" undertaken in other countries to examine where and how SoTL has been incorporated. It shows the different ways that institutions have defined SoTL with some having defined it as research into teaching and learning, some as improving teaching practice, some as establishing a strong link between teaching and the research of the discipline, and some with various combinations and permutations of these three. They examine the extent to which the rhetoric has translated into action through SoTL publications and SoTL activities, noting how workload and culture can impact negatively on engagement with SoTL activities.

In the second of these two papers, Denise Chalmers charts SoTL's relationship with institutional reward and recognition in her paper "Progress and challenges facing the recognition and reward of scholarship of teaching in higher education". This paper examines in detail the history, drivers and barriers to rewarding and recognising SoTL in institutions including the teaching quality movement, changing employment practices, research assessment exercises and the ranking of universities, with particular reference to North America, Australia and the United Kingdom. She concludes that despite the many drivers, reward and recognition of SoTL through promotion is still proving elusive.

Three papers examine specific initiatives within institutions, and in so doing, identify some of the tensions between institutional values and conceptions of SoTL and the opportunities for SoTL that arise. Iris Vardi and Robyn Quin's paper, "Promotion and the Scholarship of Teaching and Learning”, compares how well definitions of SoTL meet the underlying expectations of promotion in Australia through an in-depth examination of a relatively new promotions policy in a large Australian university. It examines how applicants for promotion reconciled SoTL with institutional expectations, particularly when applying for promotion to the higher levels of "Associate Professor" and "Professor". The paper examines whether current definitions of SoTL provide sufficient depth and breadth to progress a teaching academic through promotions to the top level of "Professor". The issue raised by this paper provides one possible reason for 
Denise Chalmers's observation that SoTL is not delivering in terms of promotion for teaching staff across universities, particularly given Haigh et al's highlighting of the different definitions in use.

In the second of these three papers, Katarina Mårtensson, Torgny Roxå and Thomas Olsson, in their paper, "Developing a Quality Culture through the Scholarship of Teaching and Learning" go beyond the valuing of SoTL through reward and recognition to addressing the institutional culture: one of the potential barriers to SoTL engagement also identified in Haigh et al's New Zealand 'stocktake'. Through examination of a comprehensive strategy undertaken in a Swedish university, they show how a quality culture in teaching and learning can be built. They argue that cultural change cannot occur without addressing academic freedom, professional identity and the ethos of the university. They claim that limiting the focus of SoTL to an academic's classroom can affect engagement as it does not match with academics' ambitions in the institution. They highlight the importance of leadership in providing the much broader sphere of influence needed to investigate and change regulations and promote development at the institutional level.

Alison Shreeve continues this examination of institutional based initiatives, in her paper, "Joining the dots: the scholarship of teaching as part of institutional research". This paper examines the types of SoTL projects arising out of one of the UK's Centres for Excellence in Teaching and Learning. Much like Mårtensson et al, and Vardi and Quin, she argues for the need for SoTL to go beyond classroom practices. Using examples of SoTL projects, she draws links between practice at the local level and the broader institutional goals, arguing that SoTL should be viewed as an overall part of enhancement of the whole university performance.

Together, the above papers highlight some of the conflicts between what institutions need from SoTL, what they need to do and the SoTL definitions in use. They also highlight new directions and opportunities for SoTL within the current institutional context. This issue, however, goes beyond the institutional perspective. It closes with a paper by Patricia Cranton challenging practitioners to think more broadly. In her paper, " $A$ transformative perspective on the Scholarship of Teaching and Learning”, Patricia Cranton calls for the proponents of SoTL to address the underlying assumptions and premises of the full range of contexts of teaching; from the discipline within which the teaching is done, through to the constraints of the institution, the community, the state and the society. She exhorts the SoTL community to look beyond the institutional pressures, demands and expectations of SoTL to fulfill Boyer's vision of SoTL as a means of developing students so that they are scholarly in their endeavours, and thus well equipped "to serve and reshape society". 


\section{References}

Anderson, D., Johnson, R., \& Saha, L. (2002). Changes in academic work. Retrieved 15th December 2006. from

http://www.dest.gov.au/archive/highered/otherpub/academic_work.pdf.

Andresen, L. W. (2000). A useable, trans-disciplinary conception of scholarship. Higher Education Research \& Development, 19(2), 137 - 153.

Australian Learning and Teaching Council. (2009). Home Page. Retrieved 17th September 2009, from http://www.altc.edu.au/

Boshier, R. (2009). Why is the Scholarship of Teaching and Learning such a hard sell? Higher Education Research \& Development, 28(1), 1 - 16.

Boyer, E. (1990). Scholarship reconsidered: Priorities of the professoriate. San Francisco: Jossey-Bass.

Burgess, T. F. (1996). Planning the academic's workload: different approaches to allocating work to university academics. Higher Education, 32(1), 63 - 75.

Burke, J., C., \& Modaressi, S. (2000). To keep or not to keep performance funding. The Journal of Higher Education, 71(4), 432 - 453.

Chalmers, D. (in this publication). Challenges facing the recognition and reward of scholarship of teaching in higher education. Higher Education Research \& Development.

Coldrake, P. (1999). Academic work in the twenty-first century. Retrieved 25th November 2006. from http://www.dest.gov.au/archive/highered/occpaper/99H/academic.pdf.

Cranton, P. (2010). Personal Communication. 9th January 2010.

Cranton, P. (in this publication). A transformative perspective on the scholarship of teaching and learning. Higher Education Research \& Development.

Haigh, N., Gossman, P., \& Jiao, X. (in this publication). Undertaking an institutional stock-take of SoTL: New Zealand university case studies. Higher Education Research \& Development.

Higher Education Funding Council for England. (2007). Teaching Initiatives. Retrieved 19th September 2009, from http://www.hefce.ac.uk/learning/TInits/

Huber, M. T., \& Morreale, S. P. (2002). Situating the scholarship of teaching and learning: A cross-disciplinary conversation. In M. T. Huber \& S. P. Morreale (Eds.), Disciplinary Styles in the Scholarship of Teaching and Learning: Exploring Common Ground. Merrifield, VA: AAHE Publications.

Hutchings, P., \& Shulman, L. S. (1999). The scholarship of teaching new elaborations, new developments. Change, 31 September/October(5), 10-15.

Kreber, C. (2002). Teaching excellence, teaching expertise, and the scholarship of teaching. Innovative Higher Education, 27(1), 5 - 23.

Mårtensson, K., Roxå, T., \& Olsson, T. (in this publication). Developing a quality culture through the scholarship of teaching and learning. Higher Education Research \& Development.

McInnis, C. (1999). The work roles of academics in Australian universities (No. 00/5). Canberra: Department of Education, Training and Youth Affairs.

McInnis, C. (2000). Changing academic work roles: the everyday realities challenging quality in teaching. Quality in Higher Education, 6(2), 143 - 152. 
Olssen, M., \& Peters, M. A. (2005). Neoliberalism, higher education and the knowledge ecolony: from the free market to knowledge capitalism. Journal of Education Policy, 20(3), 313 - 345.

Paewai, S., Meyer, L. H., \& Houston, D. (2007). Problem solving academic workloads management: a university response. Higher Education Quarterly, 61(3), 375-390.

Shreeve, A. (in this publication). Joining the dots: the scholarship of teaching as part of institutional research. Higher Education Research \& Development.

Smith, R. (2001). Expertise and the scholarship of teaching. New Directions for Teaching and Learning, 86, $69-78$.

Taylor, J., \& Taylor, R. (2003). Performance indicators in academia: an x-efficiency approach? Australian Journal of Public Administration, 62(2), 71 - 82.

Trigwell, K., Martin, E., Benjamin, J., \& Prosser, M. (2000). Scholarship of Teaching: a model. Higher Education Research \& Development, 19(2), 155 - 168.

Vardi, I. (2009). The impacts of different types of workload allocation models on academic satisfaction and working life. Higher Education, 57, 499 - 508.

Vardi, I., \& Quin, R. (in this publication). Promotion and the scholarship of teaching and learning. Higher Education Research \& Development.

Weston, C. B., \& McAlpine, L. (2001). Making explicit the development toward the scholarship of teaching. New Directions for Teaching and Learning, 86, 89 - 97.

Willox, A. C., \& Lackeyram, D. (2009). (Re)Considering the scholarship of learning: inviting the elephant in the room to tea. International Journal for the Scholarship of Teaching and Learning, 3(1), 1 - 16.

Winter, R., \& Sarros, J. (2002). The academic work environment in Australian universities: a motivating place to work? Higher Education Research and Development, 21(3), 241 - 258. 